\title{
Institutional Logics and Social Responses to Covid - 19 Outbreak and Lockdown: Case of Bosnia and Herzegovina
}

\author{
Jelena Gaković, 1 Tatjana Žarković ${ }^{2}$
}

\begin{abstract}
In this paper we explore social responses, attitudes and social practices of everyday life in the midst of a complete social closure at an early stage of corona crisis, based on original empirical survey data collected via online questionnaire $(\mathrm{N}=352)$ during the lockdown and state of emergency in Bosnia and Herzegovina. Aiming to analyse social implications of the ongoing crisis and directions for future research we have particularly focused on several dimensions: work, free time and everyday activities, attitudes towards the new uncertainty and specific needs of different social groups in the context of crisis. Social responses to novel living circumstances have highlighted problems related to the status of vulnerable groups present from before in a society that is most commonly categorized as a country in transition marked by post-war challenges. Results show that established discrimination practices have resurfaced while vulnerable social groups' living conditions have significantly aggravated even early at the times of pandemic emergence.
\end{abstract}

Keywords: Covid-19 pandemic, transition society, risk society, fear, lockdown responses, vulnerable groups

\footnotetext{
1 J.Gaković

University of Sarajevo, Faculty of Philosophy, Dept. of Sociology

Franje Račkog 1, 71000 Sarajevo, Bosnia and Herzegovina

(D) jelena.gakovic@ff.unsa.ba

2 T.Žarković

University of Sarajevo, Faculty of Philosophy. Dept. of Sociology

Franje Račkog 1, 71000 Sarajevo, Bosnia and Herzegovina

tatjana.zarkovic@ff.unsa.ba
} 


\section{Introduction}

Sudden cessation of social life caused by COVID-19 pandemic, a month-long lockdown as well as the repetitive (miss)use of "social distance" buzzword in the public discourse, called upon sociologists to offer their reflection on the present social condition dubbed in the media as "corona crisis". As research on pandemic' social immediate effects gained momentum many researchers have distributed surveys or published essays and their observations, while social science associations spontaneously called for papers sought to elaborate and analyse the social changes unfolding before our eyes. Aiming to analyse social implications of the ongoing crisis i.e. in an effort to answer the main research question: how has the emergence of COVID-19 pandemic affected the ordinary citizens' social life, a particular focus was placed on several aspects: work, free time and everyday activities, attitudes towards the new uncertainty and specific needs of different social groups in the context of the crisis.

Moreover, our additional objective was to identify directions for future research by recognizing patterns based on the analysis of the original empirical surveys' data collected online during the month of April, 2020. The questionnaire consisted of 56 questions, a combination of close-ended, open-ended and matrix questions. It was divided into 8 subsections, which will be discussed in further detail later in the Methods section of this paper. Convenience sampling was used allowing each adult individual with internet access to take part. One of the limitations of our online survey that needs to be acknowledged is underrepresentation of elderly population over the age of 65, disclosing yet another cause of social exclusion of this vulnerable group - most likely lack of access to technology or internet. What is evident from the responses we received is that novel living circumstances caused by the pandemic have indeed exposed pre-existing problems related to the status of vulnerable groups in Bosnia and Herzegovina, a country most commonly categorized as a developing country in transition marked by post-war challenges. These distinctive attributes of the social context in question may be of interest for a number of reasons, but especially for the upcoming comparative studies looking for contrast or similarities between societies during the social isolation periods.

In the following sections we engage with some relevant sociological scholarship and concepts to explore how the early pandemic lockdown and social isolation has affected respondents of our survey. The paper also offers a detailed timeline of the course of events, the lockdown and measures taken and then moves on to discuss 
the main findings and results. The final section addresses possible directions of the future studies and provides summary together with preliminary conclusions.

\section{COVID-19 State of Emergency in Bosnia and Herzegovina}

The state of emergency in developing transition countries has especially brought to the fore and emphasized Beck's (1992) claim that hazards and risks are "democratic" as they do not choose victims, but that social responsibility, help and care are marked by hierarchies in the society. The proclamation of pandemic due to global spreading of corona virus COVID-19 in March, 2020 and the first cases of disease in Bosnia and Herzegovina have brought about different epidemiological compulsory measures and recommendations for citizens in order to prevent disease spreading and to protect public health. Media reports with fast-growing number of the COVID-19 infected internationally and especially the experiences from the neighbouring European countries conveyed the message of an approaching crisis. Along with obscure facts about a novel kind of virus circulating via established globalization routes and info on modes of its transmission between people causing feelings of "fear and uncertainty" (Bauman, 2007). Beside news reports with statistics on the infected cases, the main media content was the information related to corona virus, campaigns for so called "social distancing" and promotion of a new concept of responsible behaviour. Recommendations included refraining from social interaction and avoiding live contacts outside of closest circle breaking habitual day-to-day routines to avoid danger and minimize risks. Agamben (2020) noted the key role of media in creating the "state of fear" at this point. General reorganization of life, schooling and business on online mode as well as complete social closure and restriction of in vivo contacts, implied the abandonment of previous life patterns and the 'new normal' which was received with unbelief, but also with humour as a coping mechanism. A compulsory measure which brought particular challenges to everybody demanded a special adjustment since it denied some of the basic rights for our own sake and in the interest of others (Etzioni, 2017).

The state of natural accident was introduced in Federation of B\&H on 17th March, 2020 and the state of emergency was introduced in Republic of Srpska on 28th March, 2020.

Police hour, which meant total prohibition of moving in time period from 18 p.m. to 5 a.m. in FBH and between 20 p. $\mathrm{m}$ and 5 a. m. in RS, was simultaneously introduced on 21st March, 2020. Following these measures further restrictions and 
accompanying decisions have been made for restricting cross-border movements which caused urgent return home for the citizens of $\mathrm{B} \& \mathrm{H}$ before the air traffic was cancelled and the airports were closed. In addition to obligatory masks and gloves, a 14-day self-isolation and quarantine were obligatory for all persons who entered the country at the beginning of pandemic.

Shortly after the state of natural accident/state of emergency was introduced, the population over the age of 65 , as most vulnerable to infection, and under the age of 18, labelled as major transmitters of infection, in Federation of $\mathrm{B} \& \mathrm{H}$ was not at all allowed to move and leave the house for almost a month, while in Republic of Srpska this restriction referred only to those over the age of 65. Quarantine was also imposed to migrants and refugees, not allowing them to go out of the camps mainly situated in the north-western parts of Federation of B\&H at the border with Croatia and EU. The epidemiological measures introduced in both parts of the country, although mostly similar were not systemically adjusted and were changing daily. That caused the additional confusion among people, as they were not sure how to behave, but also some polarisation and turmoil appeared in the public sphere as people doubted about which measures were more adequate and wondered if the citizens from one entity would jeopardize those from another one by behaving according to different rules.

The police hour implying total prohibition of moving was intentionally introduced in April because of forthcoming Easters (12th April/19th April) in order to avoid family gatherings with more people and new potential clusters. Afterwards, on 22nd April, The Federal Constitutional Court made a decision which confirmed that prohibition of moving for the persons over 65 and under 18 violated their human rights. Just under the pressure of this decision, on 24th April, in FB\&H, limited moving was allowed for persons over the age of 65 on Mondays, Wednesdays and Fridays from 9 a.m. to $13 \mathrm{p}$. m. and for the population under the age of 18 were allowed firstly just to drive in cars and later in some locations outside the house on Tuesdays, Thursdays and Saturdays from 14 to 20 p.m., On 24th April, in Federation of B\&H, police hour was revoked, the same thing happened to obligatory 14-day quarantine for all people who entered the country or were in contact with those infected by COVID 19.

According to daily media appearances of the members of crisis staff it could be concluded that the situation was getting better, although even then, after the first shock, public polemic started on the things like: justification and logic of the measures, number of tested persons, distribution of protection equipment which 
was donated because in free sale there was a shortage of disinfectants, masks and gloves. Prescribed fines for not wearing masks in public were in amount higher than the minimum prescribed wage in the country. The measures introduced for public health's sake started to effect economics and work places in service industry sector and they especially had impact on the most vulnerable social categories. Before the International Labour Day in Bosnia and Herzegovina some measures were deliberately imposed again - police hour, visiting the locations of picnic areas to check if the measures for keeping distance and gathering restriction were being followed. Later on (5th May) the measures were revoked. On 11th May already, most service facilities were reopened as well as hairdresser's and cosmetic salons, fitness centers, private dental clinics and other service activities. Life was getting back on track with the measures of 2 -meter distancing and wearing personal protective equipment. Educational institutions remained closed. On 20th May the state of emergency was cancelled in RS, on 31st May the state of accident caused by corona virus in FB\&H area ended.

\section{Methods, Sample and Socio-Demographic Data}

With the aim to observe how the situation described affected the fragile social relations in Bosnia and Herzegovina, an online questionnaire was distributed and filled by respondents during the month of April, 2020. The questionnaire consisted of 56 questions, a combination of close-ended, open-ended and matrix questions. It was divided into 8 subsections; the first one contains a set of questions related to general attitudes, opinions, practices linked to newly formed situation of virus COVID 19 pandemic; the second and the third subsections include questions about work, work relationships and financial situation; the fourth subsection contains a set of questions about free time and everyday activities schedule; the fifth and the sixth ones contain a set of questions about general state of health, family and housing conditions; the seventh subsection is focused on questions about specific social groups and responses to their needs while the eighth set is related to general socio-demographic data.

In order to understand the perspective of persons who responded to the questionnaire we will describe briefly our population sample. 352 persons mostly from Bosnia and Herzegovina answered the questions (40\% from Federation, 36\% from Republic of Srpska, 0,5\% from District of Brčko) The questions were answered mostly by highly educated persons (70\%) and persons with secondary school graduation (24\%), only $5 \%$ persons with vocational school and a negligible percentage of those whose schooling is lower than vocational level. Women were 
dominant with $78 \%$ and also persons from bigger urban milieu with $63 \%$. Then, we have $30 \%$ of people from smaller urban places while population from rural areas was underrepresented with only $8 \%$. The persons over the age of 65 were also underrepresented, only 1 person, and the persons between 50 and 65 had 10\% in total, while the highest percentage of respondents are in their thirties $38 \%$, followed by those in their twenties $31 \%$ and the ones in their forties $21 \%$. Underrepresentation of persons over 65 can be explained by the fact that the questionnaire was responded online, what shows the additional isolation of this population, but any other approach was difficult to perform in the period of closure and isolation.

In our sample there were $7 \%$ persons who got fired in April or put on hold temporarily with no working tasks and no incomes whereby the gender difference was not statistically significant here. Although the respondents are high educated people mostly persons from bigger towns, where resources, services and work places are present to a larger degree, the facts about incomes shown that even "privileged citizens" of the countries in transition have very unfavourable financial position. Thereby $18 \%$ persons have no income, $8 \%$ people earn less than 250 euro and $28 \%$ respondents have personal incomes from 250 to 500 euro. So, more than a half (54\%) of total number of respondents have monthly incomes to 500 euro, where gender dimension has no significance and the difference between men and women exist but is only a few percent. The percent of $27 \%$ belongs to 500 to 750 -euro category, then, $13 \%$ in total are in the category of those who earn from 750 to 1250 and more. Gender dimension has no statistical significance in our population sample when personal incomes lower than 750 euro are concerned, but regarding higher incomes there is a greater percentage difference where in the category of 1250 euro and more the number of men is doubled (men $11 \%$, women $5 \%$ ), which confirmed an important effect of so called 'glass roof' for women in developing countries.

\section{Public Attitudes, Covid-19 Outbreak and Lockdown}

In these unique social circumstances where the world stopped for a while and usual bustle and overload were blocked, especially in big cities where the citizens were obliged to close themselves into their own private spaces, the question which arose was about the experience of restricted moving and obligation to stay inside. We should keep in mind that the questionnaire was responded mostly by high educated persons from urban milieu whose incomes are over the average in the country. The 
experience mentioned was rated as totally "positive because of more available time for themselves and others' by $24 \%$ of respondents, $44 \%$ of respondents rated it as 'demanding, but with more quality time for themselves and others', which makes total of $68 \%$ of sample where the obligation of closure into private spaces and decreasing bustle were positively rated in April 2020. Some 19\% of respondents rated it negatively and for $12 \%$ of persons the situation was not changed comparing to previous period.

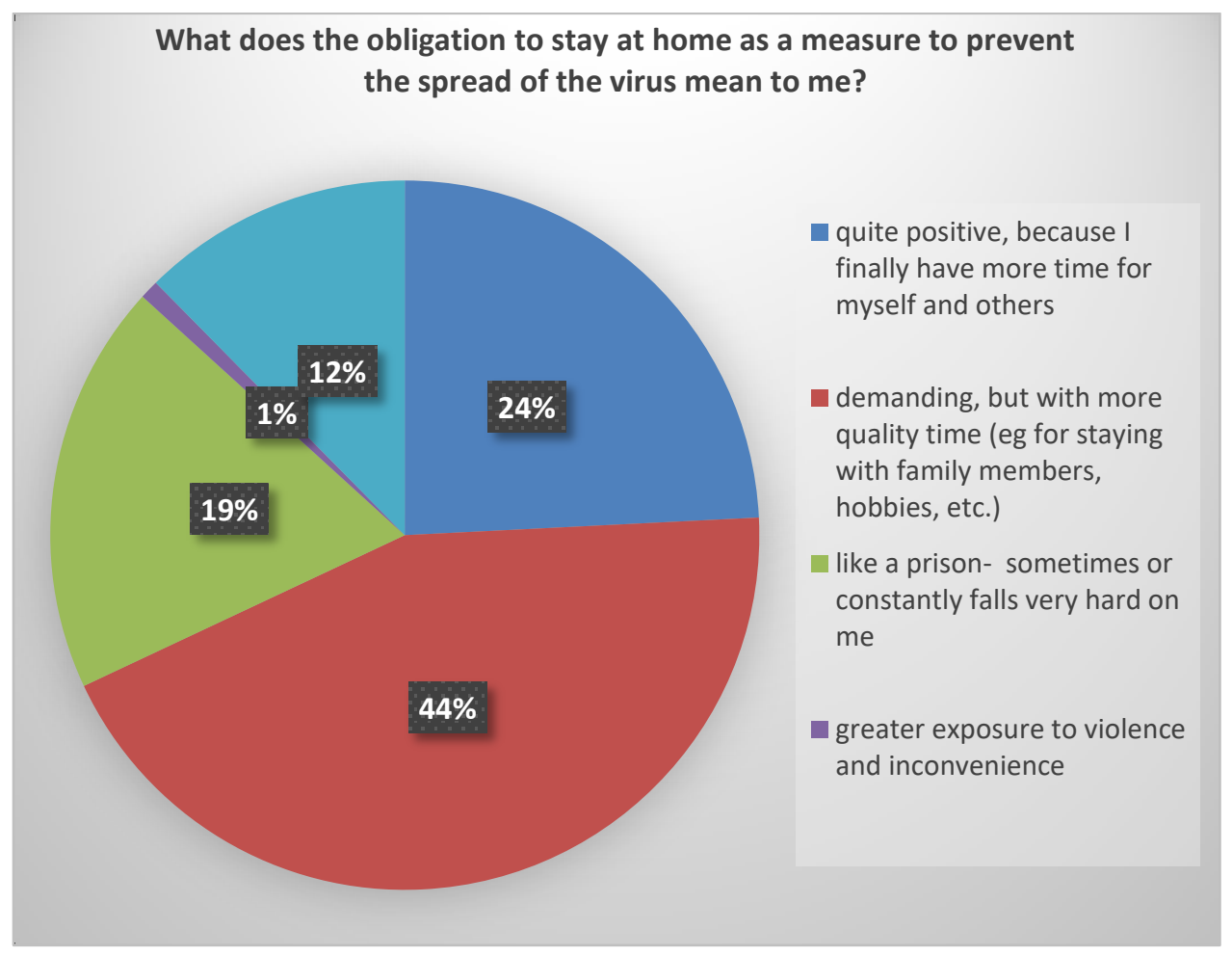

Chart1. Respondents' positive and negative experiences during lockdown

The respondents have given a satisfactory grade (average 3.8 whereby the highest one is 5) to availability of forehand, adjusted and useful information regarding pandemic in local community. There is no difference between the responses from villages, big cities and small towns and the reason could be found in the fact that all respondents combine more information sources, mostly through internet portals (77\%), TV shows (76\%), rarely through official websites of relevant institutions on the Internet (46\%).

Those who grade availability of information as unsatisfactory most often explain that information provided to the public is in many instances contradictory and confusing and assign the responsibility to politicians who are perceived to use 
media for causing confusion and panic. The respondents also mention deficiency of information at municipal and local levels, emphasizing that at the local level employers lacked to give useful and forehand information about work methods and procedures.

The persons with hearing impairment grade availability of information as bad in some cases and explain that there was insufficient use of sign language and subtitling at TV transmissions, journals and news. Opinion about the temporary measures of lockdown launched by government officials is mostly positive and in $70 \%$ of cases the respondents consider them justified and adequate while $10 \%$ of them think that the measures are too sharp and in contrast to it, $11 \%$ of them say that the given measures are not strong enough. The reason for negative grading of the measures respondents see in the fact that they do not support the methods of the introduced measures because people were not timely informed and prepared which caused dismay. It is also pointed out that any kind of total prohibition of moving with no possibility for leaving the house is ill-advised because it could jeopardize mental and physical health and well-being of the persons related.

Beside that the respondents say that there is a problem of insufficient communication with the citizens at bringing the measures out and impassivity to specific problems. This fact is also stressed in the answers to the question 'Do you think that the state will take care of the persons whose incomes were blocked because of the measures of prevention of virus spreading?' where only $5 \%$ of the respondents answer that the state will 'compensate the losses in an adequate way' and 'give a partial help' for $23 \%$ of them. The most common answer among the respondents is 'no, because the state has never taken care about social security of its citizens' ant its $38 \%$, then for $33 \%$ of them 'if there are some measures for help, I am afraid they won't reach the most endangered persons'. In this answer the variables of gender, personal material condition or place of living have no significant impact. 


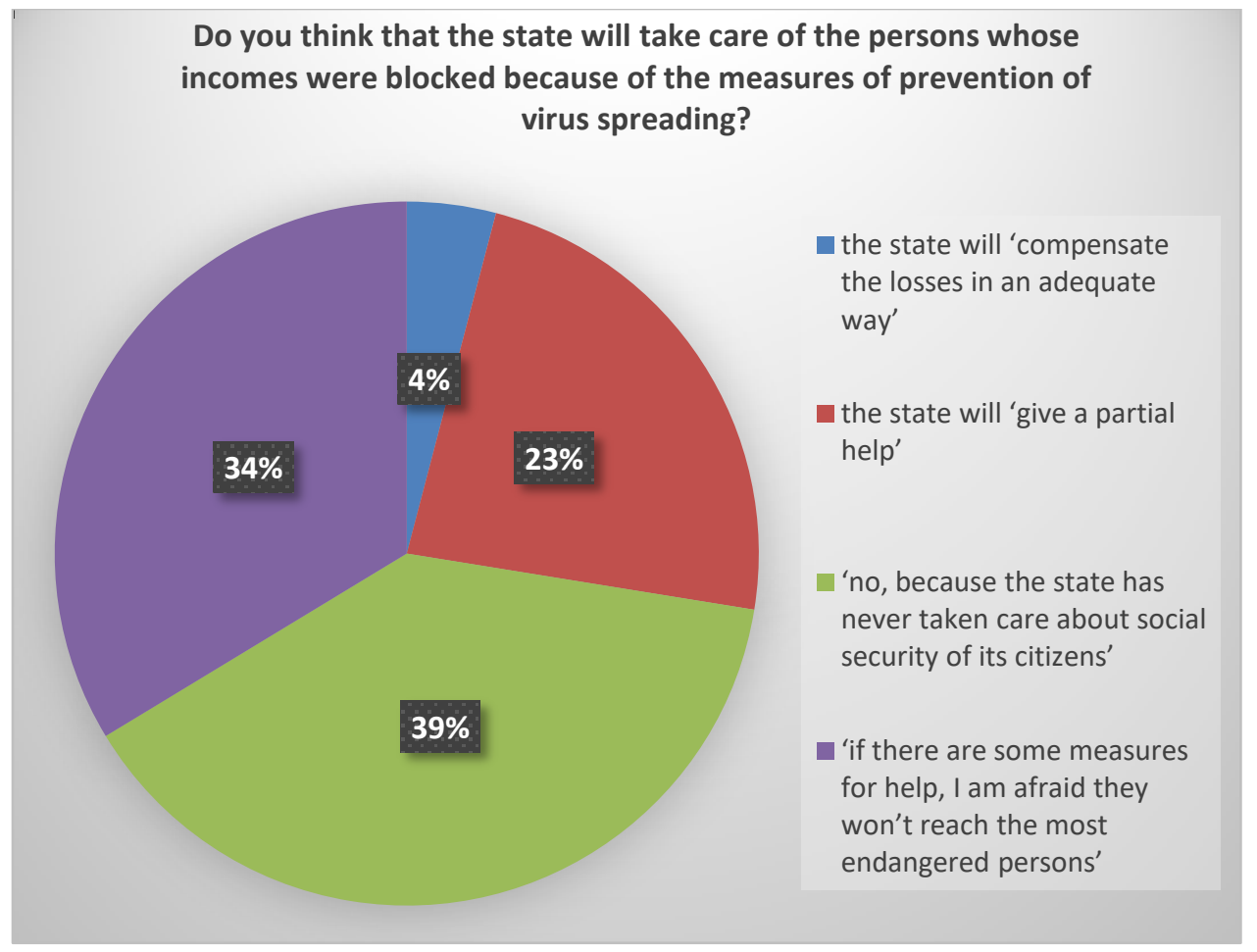

Chart2. Trust in state institutions to compensate the job loss due to pandemic

There is a general impression that the citizens' attitude towards the introduced measures is connected with their opinion about the cause of danger. The respondents mostly (in 42\% cases) assess the danger caused by virus COVID 19 as 'real danger of virus which spontaneously originated in nature and it is not the first case in history'. In $23 \%$ of cases they think that 'real danger of virus originated in nature as unique and unusual reaction of nature caused by technology development and/or insufficient care about ecology'. There are some respondents (11\% of cases) who don't know how to assess or don't want to, and in $25 \%$ of cases they think it is an 'imposed danger consciously conducted with a specific intention'. 


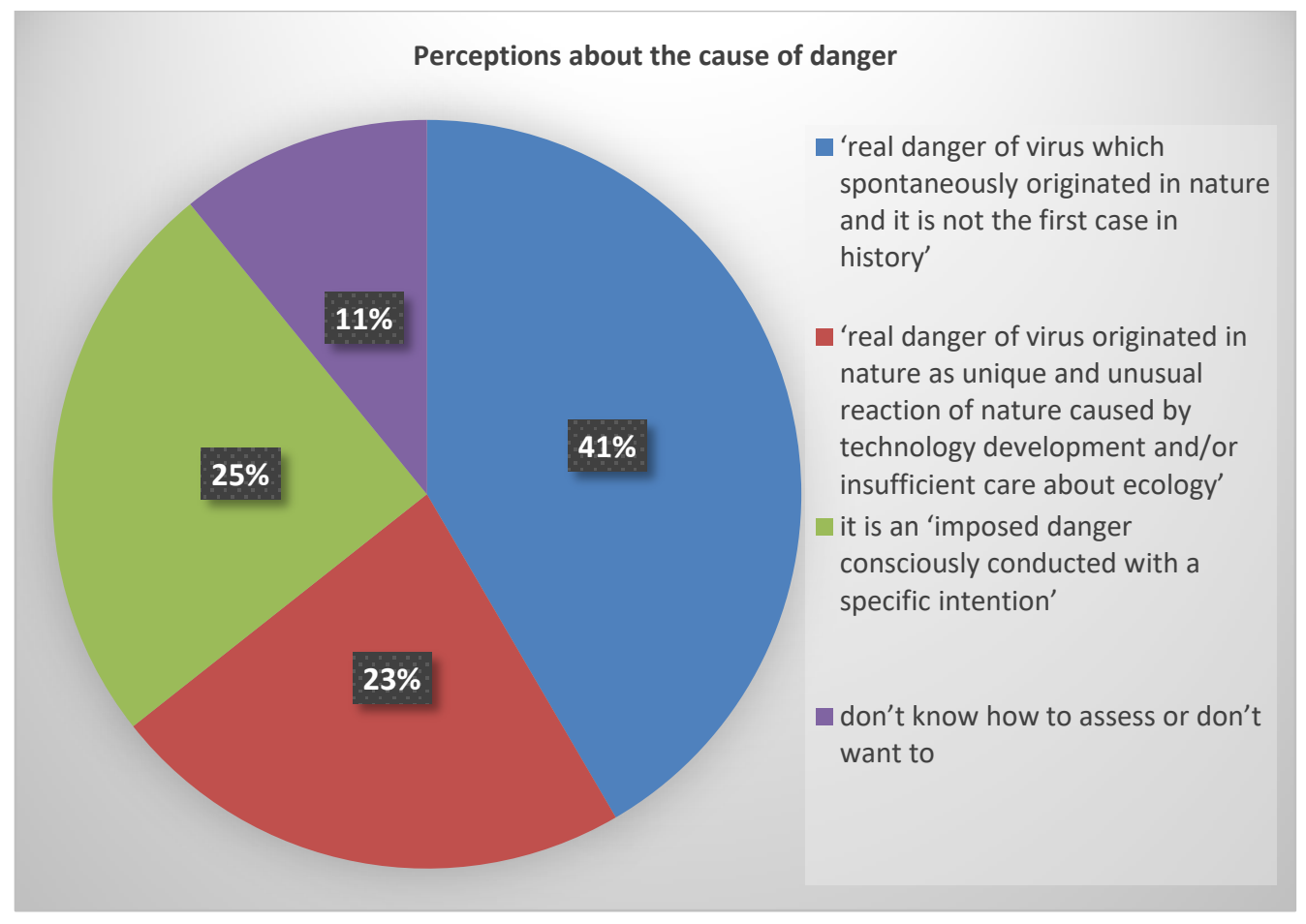

Chart 3.Perceptions towards the cause/ nature of danger

The persons who think that it's an imposed danger that was consciously conducted explain their opinion showing mistrust into official information and providing the argument that panic was created and well-staged for the sake of economic and political interests of the elite, often mentioning that real danger does not exist at a degree it is shown. Even those who are placed at the opposite side of the scales and support the opinion that the virus is a real danger spontaneously originated in nature also think that newly created situation is being misused by economic and political elites. So, the persons who explain the danger through 'conspiracy theories' also explain the problem of misuse through interpretation of the events which were supposed to have happened/ or were to happen (e.g. 5G net, an argument that the virus was made in a laboratory, predicting manipulation through vaccination), while the persons who assess the danger as real are more focused on concrete current events.

The answers to the previous question affect the next one which is about migrant crisis in the time of pandemic; the more people are inclined to conspiracy theories, the less they give support to migrants. The respondents mostly think 53\% that migrant crisis in the time of pandemic is 'the problem to be dealt with by the institutions and international organizations', in contrast to the second group of 
answers with $31 \%$ of responses where they say that it is 'the problem we all should try to solve so to protect the lives of migrants and refugees'. 10\% of respondents claim that it is 'the problem which seriously jeopardizes us and needs radical solutions and prohibitions regardless the seriousness of consequences for migrants', while $5 \%$ of them declare that it is 'the problem we should not be engaged in at the moment, nor anybody the else should, because our lives are the most important now'.

\section{Vulnerable Groups' Experiences of Social Closure}

In our sample almost one third 34\% of persons identified themselves as members of specific groups which claim that they have been treated in a different way regarding the rest of population because they are: single parents $6 \%$; persons with disabilities $7,4 \%$ or their close relatives $1,4 \%$; national or ethnic minority $3 \%$; LGBT $2,3 \%$; unemployed person 6\%; for residence status $1,4 \%$. In $64 \%$ cases persons who identified themselves as members of specific groups think that their specific needs are not sufficiently taken into account when making decisions on protection and prevention measures.

All persons who declare themselves as single parents in our sample are women and it should be noted that the persons from our sample who declared themselves as single parents significantly more often live as tenants (21\%) with regard to the rest of subpopulation (13\%), which emphasizes patriarchal patterns dominant in Balkan countries. An additional fact worth knowing is that in total sample of respondents there is great percentage of women (65\%) who live in 'private properties owned by someone else from the family (husband, father, mother, etc.)', while this number is decreasing in the share of single mothers (38\%).

This fact is significant because in their comments on the needs of specific groups the respondents often say that in the measures taken to help "nobody mentions the people who live in rented flats and how they pay for them regarding economic situation'. Single parents bring up the problem of alimony pay-out totally or partially, then there is babysitting problem for single mothers who had to work and kindergartens were closed, then general lack of measures for support and help for one-parent families because they are not mentioned as a special category so they were disenabled to get any help.

Persons with disabilities explain in detail their unfavourable position most often highlighting the lack of support services. In their explanations they raised doubts if 
adequate care, help and assistance will be provided in collective accommodation. Also access to health care and education is precarious especially access to education for the persons with intellectual difficulties without the possibilities of support and personal assistants. The problem of uneven help and support was also noted at local community level. In the responses about unfavourable position of religious and ethnic minorities most respondents refer to negligence of Roma communities as the most vulnerable ones.

Unemployed persons also bring out the problem of negligence and invisibility and they have additional worries about their status in the time of pandemic because of crisis caused by global economic stoppage. There is also a problem of the employees who work in informal sector or under the employment contract for definite period with no unemployment insurance and therefore right for support.

When we compare the respondents' schedule of daily activities before and after the measures of restricted moving we can see that significantly less time is dedicated to paid work, $14 \%$ of them spent maximal 3 hours on paid work, $19 \%$ of them spent maximum 6 hours on it and $66 \%$ of them spent 6 or more hours on paid work activities before the imposed measures. After the lockdown the percentage is significantly moving towards less time for paid work activities showing that $40 \%$ of respondents were working maximum to 6 hours daily and $23 \%$ out of them worked 1 to 3 hours.

Before the imposed obligation for staying at home the influence of gender on work schedules was not statistically relevant but after the measures it has a significant role which means that women spent less time on working tasks because of home isolation burden, home and care work, and online schooling of their children.

Work performance rate for those who were working in a modified regime is relatively high despite less working time, it is 4,5 (1 means significantly lower work performance, 7 means the same as before). The respondents dedicated more time to the activities with their children and to the house chores compared to earlier period. Men spent notably less time regarding women on house chores before the lockdown, and during the lockdown the time spent increased for men where we can still note a difference but not of high relevance.

\section{Conclusion}

Although the measures introduced due to corona virus pandemic are global ones and have much in common in different parts of the world, they are nonetheless 
taking place in specific socio-political contexts and vary in its approaches. Citizens of Bosnia and Herzegovina and its neighbouring countries have experienced some of the most stringent institutional responses combining lockdown, curfew and selfisolation. Despite the fact, presented research results show that surprisingly great number of respondents rated the obligation of restricted moving and staying at home positively.

On the other hand, when it comes to the public trust in government in taking care about job loss compensations and social security in post-corona times, evidence uncover very low levels of confidence. Moreover, when specific social groups are concerned we find that the relationship of authorities in the countries in transition towards their inconvenient position is extremely bad, which is more notable in the time of pandemic. There is also a problem of multiple reasons for inconvenient position (e.g. women's case, single mother, female tenant) where the decision makers showed no sensitivity. Results support the thesis that, in the time of general danger, the measures have been created according to an average citizen instead of protecting the most vulnerable groups first. It is necessary to examine the willingness and capacity of community at all levels to meet the needs of the most endangered categories of society during crises. It is also important to investigate inter-institutional cooperation in the time of pandemic especially the type, intensity and relationship with international agencies which was very unsatisfactory in the period this work was being written. While it will certainly take time to understand longer-term consequences of corona crisis on economic, social and psychological aspects of people's lives, it is important to continue with research including later phases of the crisis with key directions identified early on.

Ongoing social developments related to the change caused by corona crisis certainly call for further detailed elaborations and social researches, especially taking into account that the state of emergency in transition and post-conflicted countries can be a suitable ground for misuse of power, for reshaping of laws and authorities and particularly for it can overturn the development and democratization process.

According to Ule (2020) we are now as human beings more than ever obliged to demonstrate "mutual assistance, solidarity and friendship" and seize the opportunity to make positive changes. However, our results indicate that vulnerable social groups' living conditions have significantly worsened due to "new normal" circumstances even at an early stage of corona crisis. 


\section{References}

Agamben, G. (2020) The invention of an epidemic, https://www.journalpsychoanalysis.eu/coronavirus-and-philosophers/

Beck ,U. (1992). Risk Society: Towards a New Modernity, Sage Publications, London.

Bauman, Z. (2007). Liquid Times: Living in an Age of Uncertainty, Polity Press, Cambridge.

Etzioni, A. (2017). The New Normal: Finding a Balance between Individual Rights and the Common Good, Routledge, New York.

Ule, M. (2020). Theorising - If We Lose Our Humanity, We Lose Ourselves, https://www.europeansociologist.org/issue-45-pandemic-impossibilities-vol1/theorising-if-we-lose-our-humanity-we-lose-ourselves 